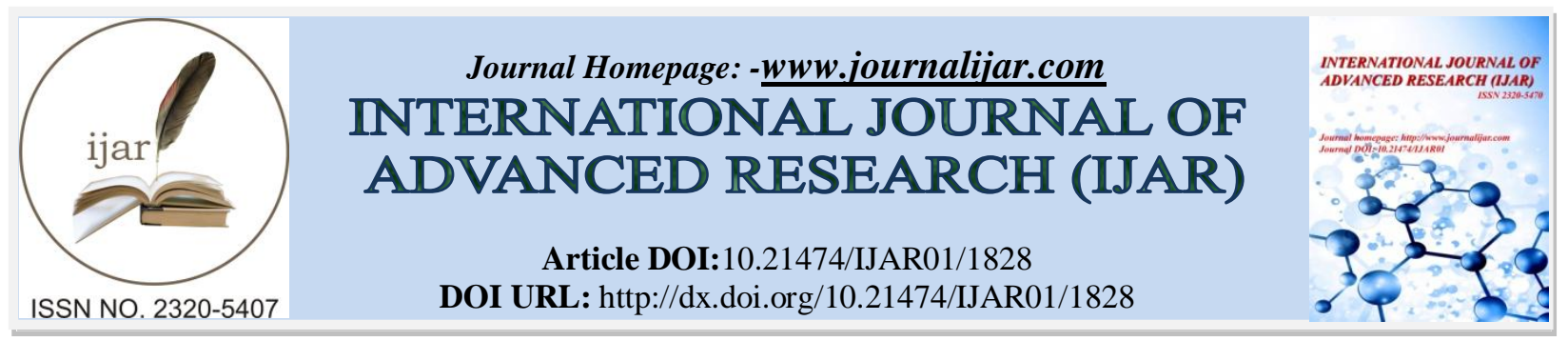

RESEARCH ARTICLE

\title{
KINETIC STUDIES OF ADSORPTION PROCESS OF CHROMIUM IONS FROM AQUEOUS SOLUTION.
}

\author{
Dimple Lakherwal ${ }^{1 *}$, V. K. Rattan ${ }^{2}$ and H. P. Singh ${ }^{1}$. \\ 1. Department of Environmental Studies, Panjab University, Chandigarh. \\ 2. Dr. S.S.B.U.I.C.E.T., Panjab University, Chandigarh.
}

\section{Manuscript Info}

Manuscript History

Received: 12 August 2016

Final Accepted: 22 September 2016

Published: October 2016

Key words:-

Granular activated carbon, adsorption, chromium, kinetics models.

\section{Abstract}

The adsorption efficiency of granular activated carbon was investigated for removal of $\mathrm{Cr}(\mathrm{VI})$ ions in a lab scale fluidised bed reactor. The effect of various parameters like $\mathrm{pH}$, contact time and initial metal ion concentration on adsorption process were investigated. More adsorption was observed at lower $\mathrm{pH}$ and optimum $\mathrm{pH}$ was found to be 3.0.The equilibrium time was observed at 420 min. With the increase in initial $\mathrm{Cr}(\mathrm{VI})$ ion concentration, the percentage adsorption decreases while the adsorption capacity $\left(\mathrm{q}_{\mathrm{e}}\right)$ increases. Maximum adsorption of $96.02 \%$ and $63.28 \%$ was found at concentration of $10 \mathrm{mg} / \mathrm{L}$ and $50 \mathrm{mg} / \mathrm{L}$ respectively. The kinetic study was performed using pseudo-first and pseudo-second order kinetic model. The process of adsorption of $\mathrm{Cr}(\mathrm{VI})$ ions was found to follow pseudo-second order kinetic model.

Copy Right, IJAR, 2016,. All rights reserved.

\section{Introduction:-}

Environmental pollution in water bodies is due to the enormous quantity and variety of chemical compounds found in the industrial wastewaters. Large amount of effluent laden with toxic heavy metals from industries is discharged into the environment posing threat to public health due to their toxic and persistent nature.High concentrations of chromium are found in wastewater released from the chemical industries especially electroplating and leather tanning industries [1]. Othersources include pigment, paper, paints, steel fabrication, mining and textile dyeing industries. Chromium salts also found their use in wood preservatives and ceramic, fungicides and rubber manufacturing [2]. In aqueous phase chromium exists in two forms: trivalent and hexavalent. $\mathrm{Cr}$ (III) is required for nutrition but upto a certain limit only. However, $\mathrm{Cr}(\mathrm{VI})$ is toxic and is found to be carcinogenic. The tolerance limit for $\mathrm{Cr}(\mathrm{VI})$ in potable water is $0.05 \mathrm{mg} / \mathrm{L}$. For releasing the hexavalent chromium into the inland waters, the tolerance limit is $0.1 \mathrm{mg} / \mathrm{L}$. The safe limit for chromium containing effluent discharge into the surface water is also $0.1 \mathrm{mg} / \mathrm{L}$ as set by the Ministry of Environment and Forest [MoEF] [3]. According to EPA, chromium inhalation causes shortening of breath, asthmatic problems, wheezing and nose and throat irritation. Continuous exposure leads to bleeding of stomach and intestine and circulatory, kidney and liver damage. Skin contact causes skin allergy, ulcers and skin irritation [4]. Ion exchange, Reverse osmosis, Chemical reduction, Electrolysis, Precipitation, Flocculation, Coagulation andNano-filtration are the most popular conventional methods used for the removal of chromium ions from the industrial wastewater. Most of the processes have one or more drawbacks and they cannot be used for removing lower concentrations of heavy metal ions. It is challenging task for the environment scientists and engineers to develop new technologies for removing heavy metals which are effective and economic [5]. Adsorption process is efficient in removing very low concentrations of metal ions and is considered more effective 
technology as compared to other methods. In the present study $\mathrm{Cr}(\mathrm{VI})$ is removed from the aqueous solution using granular activated carbon (GAC) in Fluidised bed reactor and the various factors affecting the process of adsorption are studied.Activated carbon is widely used adsorbent because of its larger surface area high adsorption capacity. GAC has a great potential to adsorb a wide range of pollutants efficiently.

\section{Experimental:- \\ Materials:-}

Granular activated carbon:-

Granular activated carbon (GAC) supplied by the Brillex Chemical Ltd. Punjab was probed in the present experiment for $\mathrm{Cr}(\mathrm{VI})$ removal as an adsorbent. It was sieved and then stored in an air-tight container.

\section{Reagents:-}

$2.828 \mathrm{~g}$ of potassium dichromate was dissolved in $1 \mathrm{~L}$ of distilled water to prepare $1000 \mathrm{mg} / \mathrm{L}$ stock solution of $\mathrm{Cr}(\mathrm{VI})$. The prepared standard stock solution of $\mathrm{Cr}(\mathrm{VI})$ was diluted to get the required initial concentration of $\mathrm{Cr}(\mathrm{VI})$ for further experiments. $0.1 \mathrm{M} \mathrm{HCl}$ and $\mathrm{NaOH}$ were used to adjust the $\mathrm{pH}$ of the solutions.

\section{Methods:-}

\section{Adsorption experiments in FBR:-}

Experiments were conducted in lab scale fluidised bed having internal diameter of $5 \mathrm{~cm}$ and $116 \mathrm{~cm}$ height. The experimental setup include FBR column, feed tank containing $\mathrm{Cr}$ (VI) solution, rotameter and centrifugal pump. $50 \mathrm{~g}$ of granular activated carbon was added to the FBR and $\mathrm{Cr}(\mathrm{VI})$ solution was pumped into column from the bottom at a constant flowrate of $150 \mathrm{~L} / \mathrm{h}$, so that the process of fluidisation can take place. Working volume of $2 \mathrm{~L}$ was taken. The samples were taken after a regular interval of $1 \mathrm{~h}$ and the residual concentration of $\mathrm{Cr}(\mathrm{VI})$ was determined using atomic adsorption spectrophotometer (AAS). The amount of $\mathrm{Cr}(\mathrm{VI})$ ions adsorbed per unit mass of the GAC was calculated from the following expression:

$$
q_{e}=\left(\frac{C_{0}-C_{e}}{W}\right) \times V
$$

Where, $\mathrm{q}_{\mathrm{e}}(\mathrm{mg} / \mathrm{g})$ is the amount of metal ion adsorbed per unit weight of adsorbent, $\mathrm{C}_{0}(\mathrm{mg} / \mathrm{L})$ is the initial metal ion concentration, $\mathrm{C}_{\mathrm{e}}(\mathrm{mg} / \mathrm{L})$ is the equilibrium concentration, $\mathrm{W}(\mathrm{g})$ is the weight of the adsorbent used and $\mathrm{V}(\mathrm{L})$ is the volume of the metal solution.

\section{Result and Discussions:- \\ Effect of pH:-}

To study the influence of $\mathrm{pH}$ on adsorption of $\mathrm{Cr}(\mathrm{VI})$, experiments were run in FBR varying the $\mathrm{pH}$ between 1 and 10 with concentration of $50 \mathrm{mg} / \mathrm{L}$ chromium solution and adsorbent dose of $50 \mathrm{~g}$. The flow rate was kept constant at $150 \mathrm{~L} / \mathrm{h}$. It is quite evident from Figure 2 that the adsorption characteristics of GAC are highly dependent on $\mathrm{pH}$ of the solution. It was observed that removal ofCr(VI) ions decreased with the increasing $\mathrm{pH}$. The optimal $\mathrm{pH}$ for the adsorption of $\mathrm{Cr}(\mathrm{VI})$ was 3.0 as maximum removal of $74.49 \%$ was observed at this $\mathrm{pH}$. This is due to the fact that at lower $\mathrm{pH}$ the $\mathrm{Cr}(\mathrm{VI})$ exists as $\mathrm{HCrO}_{4}^{-}$. The adsorbent at low $\mathrm{pH}$ is protonated having $\mathrm{H}^{+}$and attract negatively charged $\mathrm{HCrO}_{4}{ }^{-}$ions which get adsorbed on GAC surface. With increasing $\mathrm{pH}$, surface of adsorbent gets deprotonated and the $\mathrm{Cr}(\mathrm{VI})$ exists as chromate $\left(\mathrm{CrO}_{4}{ }^{2-}\right)$ ions resulting in electrostatic repulsion. This decreases the percentage adsorption of $\mathrm{Cr}(\mathrm{VI})[6,7]$. All the further experiments were conducted at $\mathrm{pH} 3.0$. 


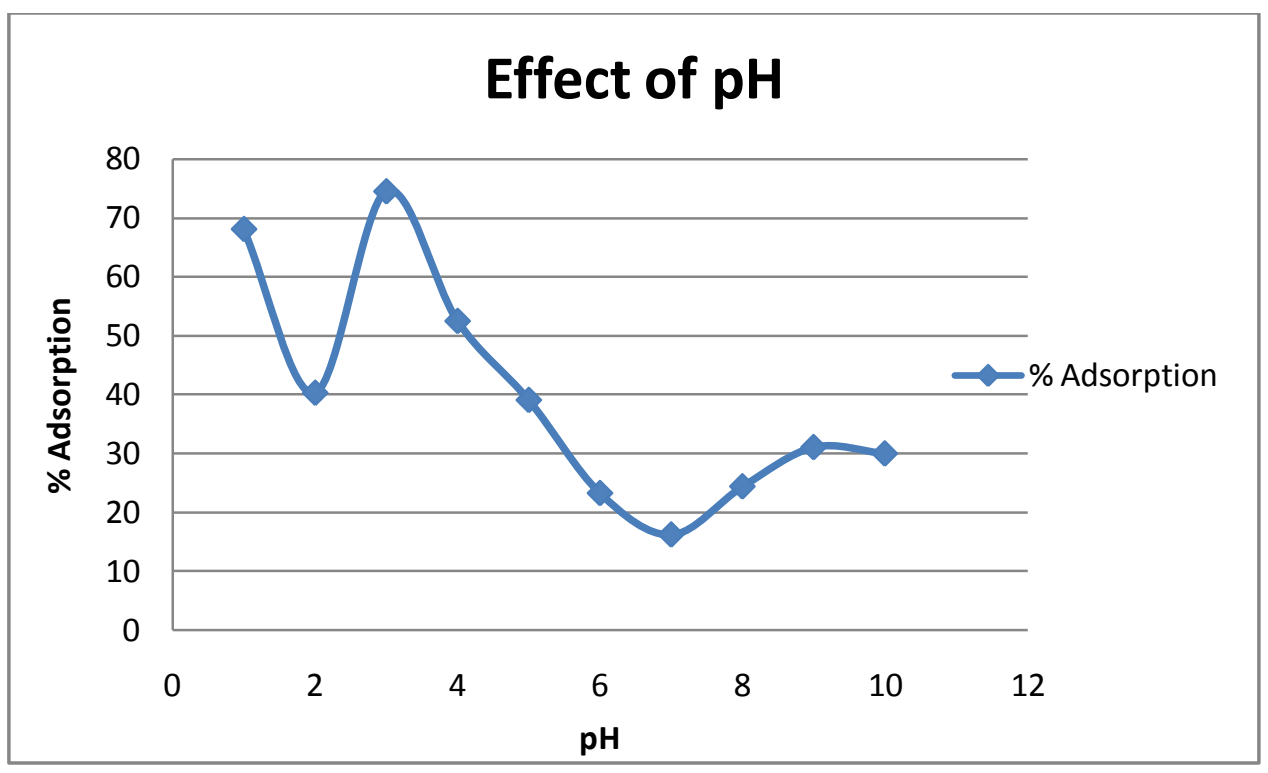

Effect of contact time:-

Figure 1:- Effect of $\mathrm{pH}$ on adsorption of $\mathrm{Cr}(\mathrm{VI})$.

The effect of contact time on $\mathrm{Cr}(\mathrm{VI})$ adsorption was measured by conducting experiment at initial $\mathrm{Cr}(\mathrm{VI})$ ion concentration of $50 \mathrm{mg} / \mathrm{L}, \mathrm{GAC}$ dose of $50 \mathrm{~g}$ and flow rate of $150 \mathrm{~L} / \mathrm{h}$. the $\mathrm{pH}$ was maintained at 3.0.There was a noticeable increase in the percentage adsorption of $\mathrm{Cr}(\mathrm{VI})$ up to $240 \mathrm{~min}$. After $240 \mathrm{~min}$ the process of removal slows down showing very little change in removal percentage reaching equilibrium at around $420 \mathrm{~min}$. The removal recorded was $56.45 \%$ at $240 \mathrm{~min}$ and reaches $63.28 \%$ at $420 \mathrm{~min}$. The initial speedy adsorption can be attributed to the enormous active sites available for adsorption. With time these active sites got filled and hindered $\operatorname{re~} \operatorname{Cr}(\mathrm{VI})$ ions to get adsorbed on GAC due to steric effect and delay the equilibrium time to $420 \mathrm{~min}$. [8,9]. The influence of contact time is shown in Figure 3. Based on the results, all the experiments were performed for 420 min to reach equilibrium.

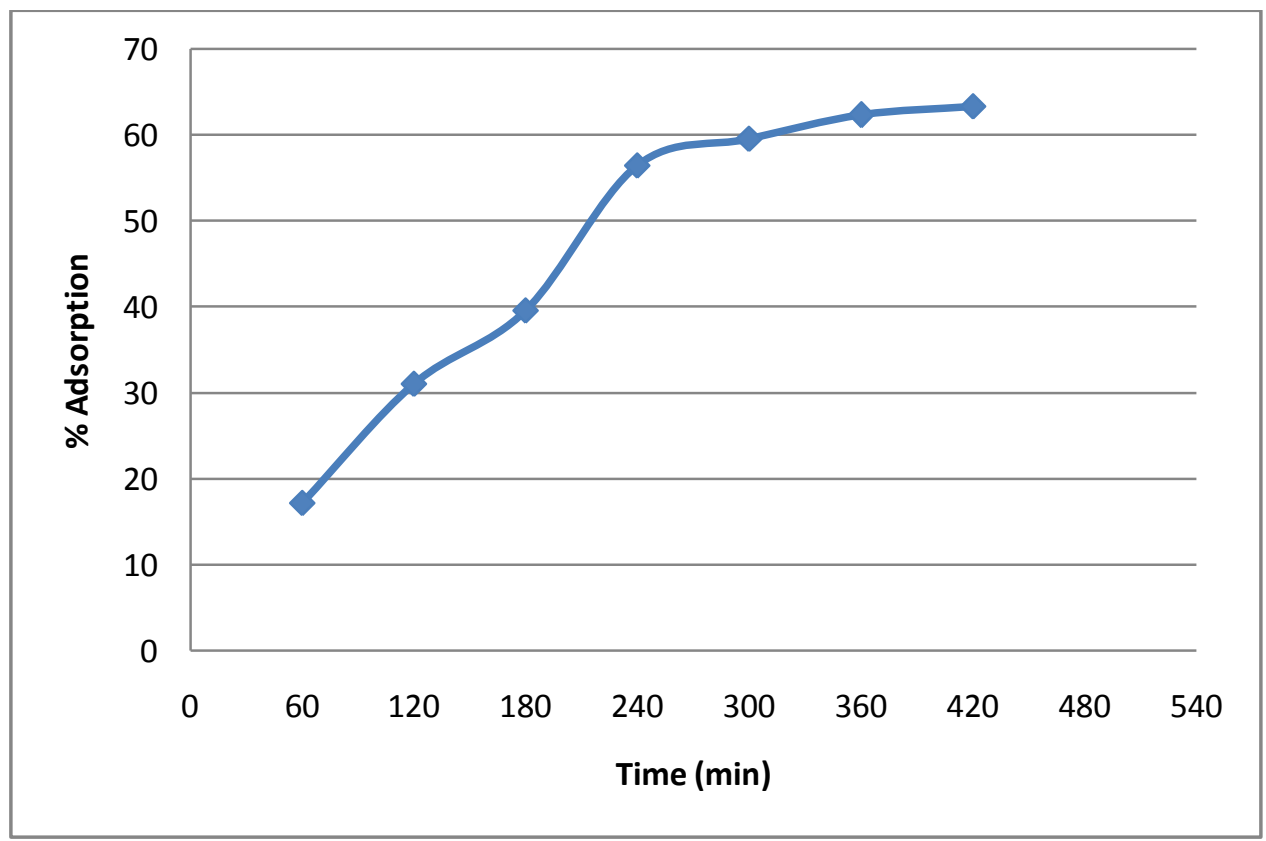

Figure 2:- Effect of contact time on adsorption of $\mathrm{Cr}(\mathrm{VI})$. 


\section{Effect of initial ion concentration:-}

The initial $\mathrm{Cr}(\mathrm{VI})$ ion concentration was varied between $10 \mathrm{mg} / \mathrm{L}$ and $50 \mathrm{mg} / \mathrm{L}$ to know its effect on removal of chromium ions. All other parameters were kept constant. The adsorption of $\mathrm{Cr}(\mathrm{VI})$ is concentration-dependent which can be clearly proven from Figure 4 showing effect on percentage adsorption and amount of $\mathrm{Cr}(\mathrm{VI})$ ions adsorbed per unit mass of GAC $\left(\mathrm{q}_{\mathrm{e}}\right)$. It was visualised that as the initial $\mathrm{Cr}(\mathrm{VI})$ ion concentration is increased from $10 \mathrm{mg} / \mathrm{L}$ to $50 \mathrm{mg} / \mathrm{L}$, the percentage adsorption decreases and on the other hand the adsorption capacity $\left(\mathrm{q}_{\mathrm{e}}\right)$ or the amount of $\mathrm{Cr}(\mathrm{VI})$ ions adsorbed per unit mass of GAC increases. The removal decreased from $96.02 \%$ at $10 \mathrm{mg} / \mathrm{L}$ to $63.28 \%$ at $50 \mathrm{mg} / \mathrm{L}$ while the adsorption capacity $\left(\mathrm{q}_{\mathrm{e}}\right)$ increased from $0.768 \mathrm{mg} / \mathrm{g}$ at $10 \mathrm{mg} / \mathrm{L}$ to $2.531 \mathrm{mg} / \mathrm{g}$ at 50 $\mathrm{mg} / \mathrm{L}$ of $\mathrm{Cr}(\mathrm{VI})$ concentration. The decrease in percentage adsorption is due to the reason that the active adsorption sites get saturated as the concentration is increased for the same amount of adsorbent dose $[10,11]$.

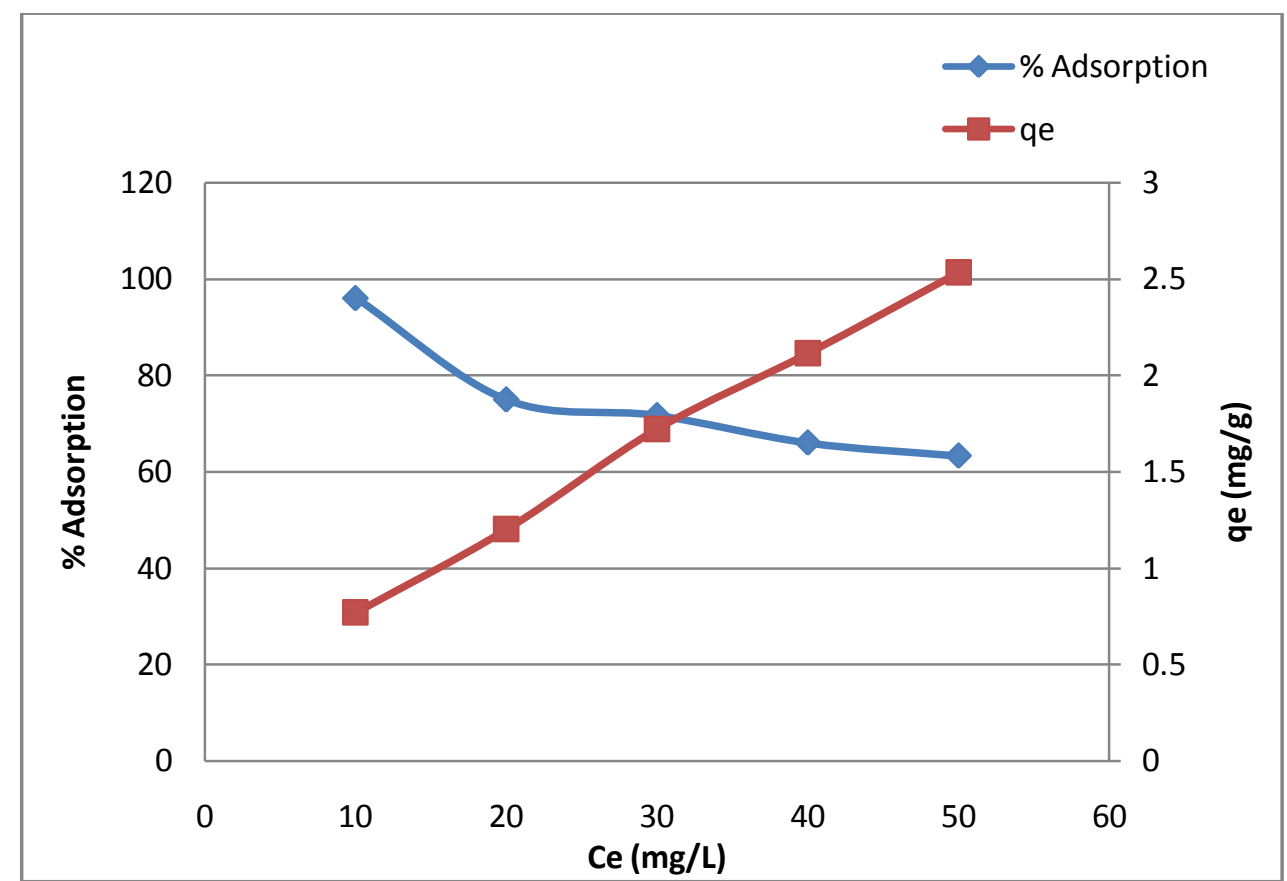

Figure 3:- Effect on initial CR(VI) ion concentration on percentage adsorption and adsorption capacity $\left(\mathrm{q}_{\mathrm{e}}\right)$.

\section{Kinetic studies:-}

Kinetic study is important to analyse the mechanism of adsorption and pathway of reactions taking place during the process of adsorption. Kinetic study also helps in designing the efficient adsorption system. The kinetics of adsorption of $\mathrm{Cr}(\mathrm{VI})$ ions onto GAC in a FBR was tested using pseudo-first order kinetic model and pseudo-second order kinetic model proposed by Lagergren. The conformity between theoretical and experimental data was evaluated using value of correlation coefficient, $\mathrm{R}^{2}$ [12].

The linear form of pseudo-first order equation is expressed as:

$$
\log \left(q_{e}-q_{t}\right)=\log \left(q_{e}\right)-\frac{K_{1}}{2.303} t
$$

Where $\mathrm{q}_{\mathrm{e}}$ the adsorption capacity $(\mathrm{mg} / \mathrm{g})$ at equilibrium, $\mathrm{q}_{\mathrm{t}}$ is the adsorption capacity $(\mathrm{mg} / \mathrm{g})$ at time $\mathrm{t}$ and $\mathrm{K}_{1}$ $(1 / \mathrm{min})$ is the pseudo-first-order rate constant of adsorption. The slope and intercept of $\log \left(\mathrm{q}_{\mathrm{e}}-\mathrm{q}_{\mathrm{t}}\right) \mathrm{vs}$. time, $t$ gives the value of $\mathrm{K}_{1}$ and $\mathrm{q}_{\mathrm{e}}$.

The pseudo-second order equation is given by:

$$
\frac{t}{q_{t}}=\frac{1}{K_{2} q_{e}{ }^{2}}+\frac{1}{q_{e}}(t)
$$

Where $\mathrm{K}_{2}(\mathrm{mg} / \mathrm{g} \mathrm{min})$ is the second order rate constant of adsorption. The initial sorption rate can be calculated from the equation:

$$
h=K_{2} q_{e}{ }^{2}
$$

The values constants $K_{2}, h$ and correlation coefficient $R^{2}$ is determined by plotting $t / q_{t}$ against time, $t[13,14]$. 


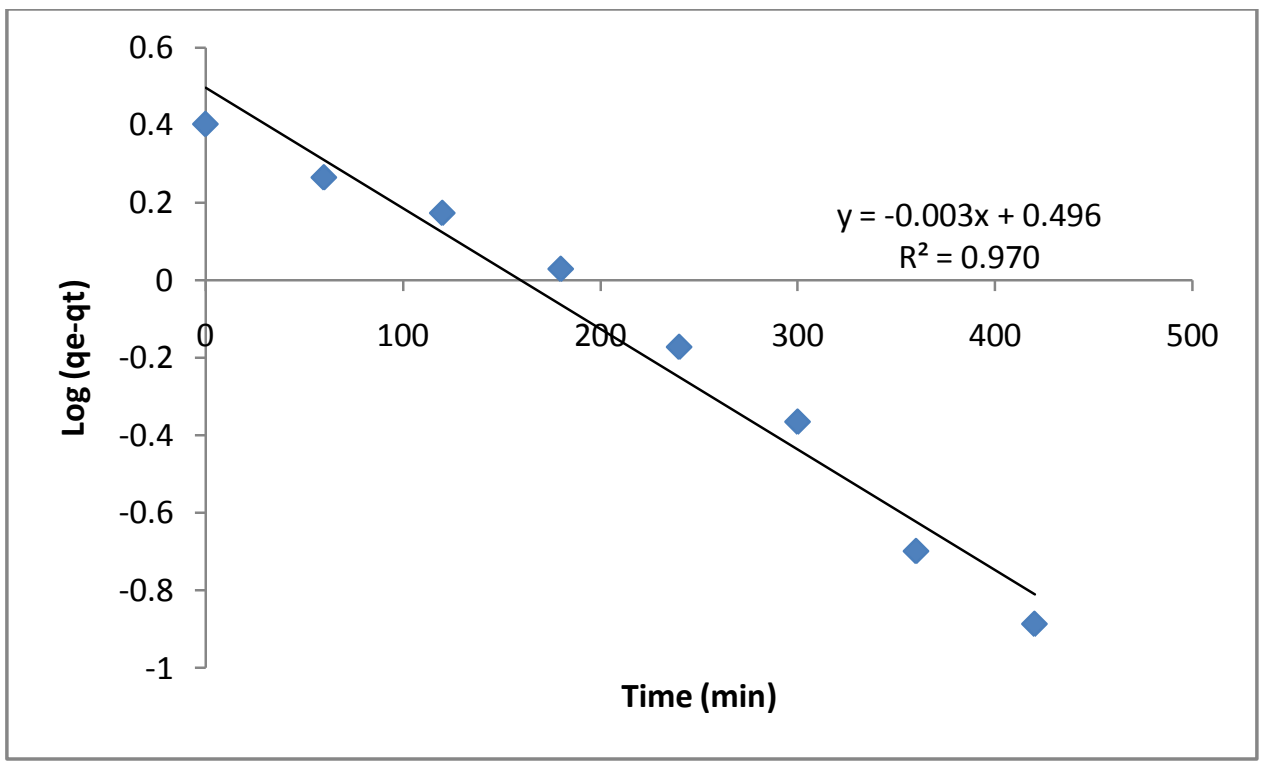

Figure 4:- Pseudo-first order kinetic plot for adsorption $\mathrm{Cr}(\mathrm{VI})$ onto GAC.

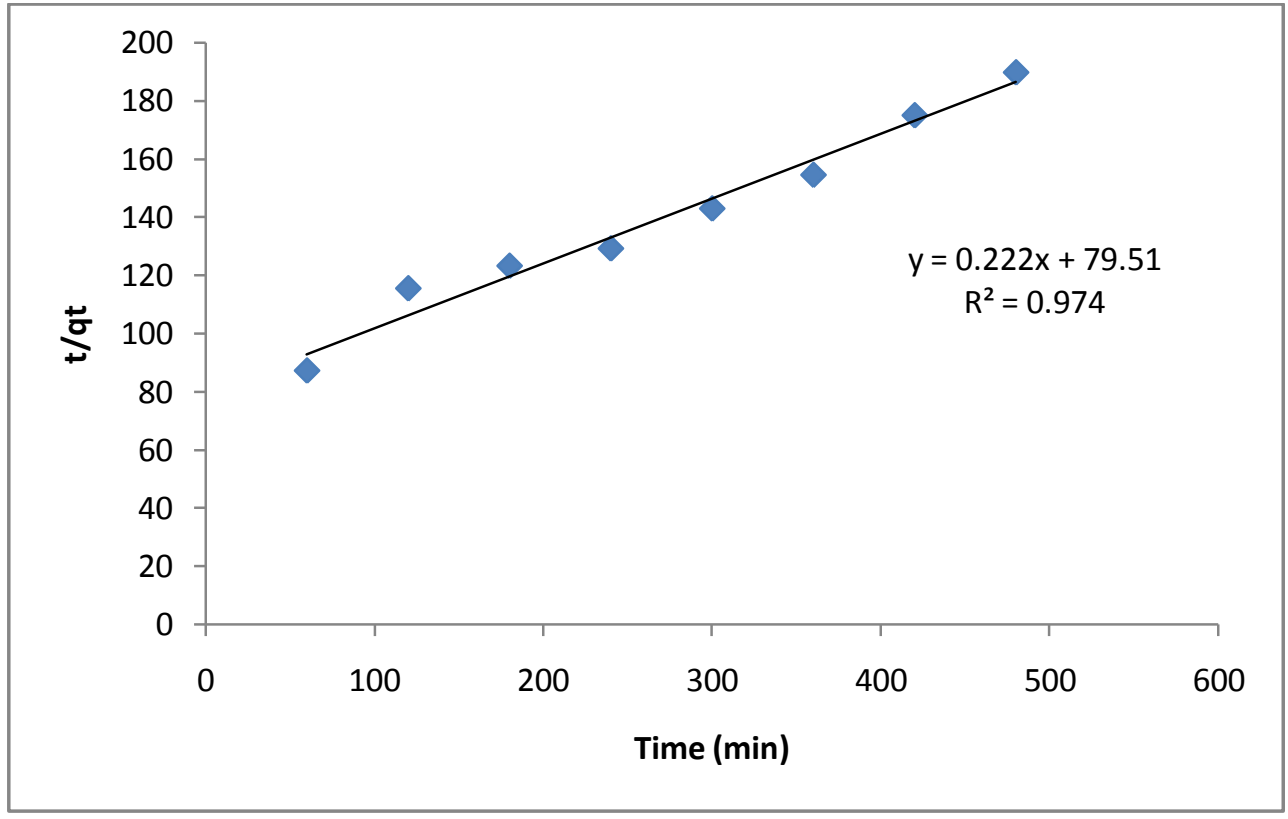

Figure 5-:- Pseudo-second order kinetic plot for adsorption $\mathrm{Cr}(\mathrm{VI})$ onto GAC

The linear plots of $\log \left(\mathrm{q}_{\mathrm{e}}-\mathrm{q}_{\mathrm{t}}\right)$ vs. $\mathrm{t}$ and $\mathrm{t} / \mathrm{q}_{\mathrm{t}} \mathrm{vs}$. $t$ for pseudo-first order and pseudo-second order are shown in Figure 4 and 5 respectively. The values of constant $K_{1}, K_{2}, h$ and correlation coefficient are tabulated in Table 1 and 2 for pseudo-first order and pseudo-second order.

Table 1:- Kinetic constant parameters obtained for Pseudo-first order kinetic model.

\begin{tabular}{|c|c|c|}
\hline \multicolumn{3}{|c|}{ Pseudo-first order constants } \\
\hline $\mathrm{R}^{2}$ & $\mathrm{k}_{1}\left(\mathrm{~min}^{-1}\right)$ & $\mathrm{q}_{\mathrm{e}}(\mathrm{mg} / \mathrm{g})$ \\
\hline 0.9704 & 0.0071 & 3.1376 \\
\hline
\end{tabular}


Table 2:- Kinetic constant parameters obtained for Pseudo-first order kinetic model.

\begin{tabular}{|c|c|c|c|}
\hline \multicolumn{3}{|c|}{ Pseudo-second order constants } \\
\hline $\mathrm{R}^{2}$ & $\mathrm{k}_{2}$ & $\mathrm{q}_{\mathrm{e}}(\mathrm{mg} / \mathrm{g})$ & $\mathrm{h}(\mathrm{mg} / \mathrm{h} \mathrm{min})$ \\
\hline 0.9743 & 0.00062 & 4.4943 & 0.01257 \\
\hline
\end{tabular}

The value of $\mathrm{R}^{2}$ is $>0.95$ for both the kinetic models but higher $\mathrm{R}^{2}$ value is observed for pseudo-second order kinetic model $[15,16]$. This shows that the experimental data fits better to pseudo-second order kinetic models for the adsorption of $\mathrm{Cr}(\mathrm{VI})$ ions onto granular activated carbon in a fluidised bed reactor.

\section{Conclusion:-}

Adsorption of $\mathrm{Cr}(\mathrm{VI})$ ions is highly dependent on $\mathrm{pH}$, contact time and initial metal ion concentration. Maximum adsorption capacity was found to be $2.531 \mathrm{mg} / \mathrm{g}$ at initial $\mathrm{Cr}(\mathrm{VI})$ ion concentration of $50 \mathrm{mg} / \mathrm{L}$. The experimental data is in correlation with pseudo-first order kinetic model. Granular activated carbon can be evaluated as effective adsorbent for removing chromium ions in fluidised bed reactor.

\section{Refererences:-}

1. Barkat, M., Nibou, D., Chegrouche, S., Mellah, A.(2009): Kinetics and thermodynamics studies of chromium(VI) ions adsorption onto activated carbon from aqueous solutions . Chemical Engineering and Processing., 48: 38-47 .

2. Babu, A.N., Krishna Mohan, G.V., Ravindhranath, K.(2016) : Removal of Chromium (VI) from Polluted waters using Adsorbents derived from Chenopodium album and Eclipta prostrate Plant Materials. International Journal of ChemTechResearch .,9: 506-516.

3. tacharya, A.K., Naiya, T.K., Mandal, S.N., Dasa, S.K.(2008): Adsorption, kinetics and equilibrium studies on removal of $\mathrm{Cr}(\mathrm{VI})$ from aqueous solutions using different low-cost adsorbents.Chemical Engineering Journal .,137: 529-541.

4. 4.Singh, A., Pal, R., Gangwar, C., Gupta, A., Tripathi, A. (2015) : Release of Heavy Metals from Industrial Waste and E-Waste Burning and Its Effect on Human Health and Environment . International Journal of Emerging Research in Management \&Technology ., 4: 51-56.

5. Ahluwalia, S.S., Goyal, D. (2007) :Microbial and plant derived biomass for removal of heavy metals from wastewater. Biores. Technol., 98: 2243-2257.

6. Dakiky, M., Khamis, M., Manassra, A., Mer'eb , M. (2002):Selective adsorption of chromium(VI) in industrial wastewater using low-cost abundantly available adsorbents . Advances in Environmental Research., 6 : 533-540.

7. Selvi, K., Pattabhi, S., Kadirvelu, K. (2001): Removal of Cr(VI) from aqueous solution by adsorption onto activated carbon. Bioresource Technology., 80: 87-89.

8. Huang,R.,Yang, B., Liu, Q., Liu, Y. (2014): Simultaneous Adsorption of Aniline and Cr(VI) Ion by Activated Carbon/Chitosan Composite.J. Appl. Polym. Sci., 1-9.

9. Ucun, H.,Bayhan, Y. K., Kaya, Y.,Cakici, A., Algur, A. F.(2002):Biosorption of chromium(VI) from aqueous solutionby cone biomass of Pinussylvestris.Bioresource Technology., 85:155-158.

10. Garg, U.K., Kaur, M.P., Garg, V.K., Suda,D.,(2007):Removal of hexavalent chromium from aqueous solution byagricultural waste biomass. Journal of Hazardous Materials ., 140 :60-68.

11. Malwade, K., Lataye, D., Mhaisalkar, V.,Kurwadkar,S., Ramirez, D. (2016): Adsorption of hexavalent chromium onto activated carbon derived from Leucaenaleucocephala waste sawdust: kinetics, equilibrium and thermodynamics.Int. J. Environ. Sci. Technol., 13:2107-2116.

12. Othman,J. A. A., Ali, R., Naushad, M. (2012): Hexavalent chromium removal from aqueous medium by activated carbonprepared from peanut shell: Adsorption kinetics, equilibrium andthermodynamicstudies.Chemical Engineering Journal., $184: 238-247$.

13. Yang, J., Yu,M.,Chen, W.(2015): Adsorption of hexavalent chromium from aqueous solution byactivated carbon prepared from longan seed: Kinetics, equilibrium andthermodynamics.Journal of Industrial and Engineering Chemistry., 21: 414-422.

14. Yadav, S., Srivastava, V., Banerjee, S., Weng, C. H., Sharma, Y. C. (2012) : Adsorption characteristics of modified sand for the removal of hexavalent chromium ions from aqueous solutions: Kinetic, thermodynamic and equilibrium studies. Catena., 100: 120-127.

15. Duranoglua, D.,Trochimczukb, A.W., Bekera, U.(2012): Kinetics and thermodynamics of hexavalent chromium adsorption onto activated carbon derived from acrylonitrile-divinylbenzene copolymer. Chemical Engineering Journal., $187: 193-202$.

16. Khezami, L.,Capart, R. (2005): Removal of chromium(VI) from aqueous solution by activated carbons: Kinetic and equilibrium studies.Journal of Hazardous Materials., B123: 223-231. 